\title{
Prognostic value of creatine kinase BB-isoenzyme in high risk newborn infants
}

\author{
V J RUTH \\ Children's Hospital, University of Helsinki, Finland
}

SUMmARY Serum creatine kinase BB-isoenzyme (CK-BB) activity was studied on the first day of life in 31 acutely asphyxiated infants, 70 infants born after high risk pregnancies (pre-eclampsia or intrauterine growth retardation, or both), and 47 very low birthweight infants. Neurodevelopmental evaluation was carried out at $2 \cdot 2-2 \cdot 5$ years. Eight infants died with, and eight without, hypoxic-ischaemic lesions of the brain, 14 had cerebral palsy, 16 had mild motor impairment, six had developmental delay without motor impairment, and 96 were normal at follow up. Infants who died with brain injury had significantly higher CK-BB activity than infants with normal outcomes (geometric mean $12 \mathrm{U} / \mathrm{l}$ ); the mean difference was $82 \mathrm{U} / \mathrm{l}$ with a $95 \%$ confidence interval from 31 to $219 \mathrm{U} / \mathrm{l}$. CK-BB in infants with cerebral palsy and mild motor impairment (geometric means 12 and $15 \mathrm{U} / \mathrm{l}$, respectively) were similar to controls. CK-BB activity after birth is predictive of neonatal death but not of neurological damage in survivors.

Perinatal asphyxia is a common cause of neonatal mortality, and survivors are at risk of permanent brain damage, mainly cerebral palsy. In a population based study the incidence of cerebral palsy of perinatal origin was $1 \cdot 1 / 1000$ live births ${ }^{1} ; 47 \%$ of the handicapped infants had been born at full term. In low birthweight infants the incidence of brain injury was inversely correlated with gestational age with an overall incidence of $6.8 \%$ in survivors. ${ }^{2}$

The classical indicators of asphyxia (the Apgar score and cord $\mathrm{pH}$ ) are poor predictors of brain damage, ${ }^{34}$ so to detect a risk of hypoxic-ischaemic brain injury in the neonatal period more specific measurements are needed.

The BB-isoenzyme of creatine kinase (CK-BB) has been considered comparatively specific for brain tissue, and increased activity in serum ${ }^{5}$ or cerebrospinal fluid ${ }^{6}$ has been associated with brain damage in adults. Increased activity of CK-BB in serum has been reported in preterm infants with intraventricular haemorrhage ${ }^{7}$ and in asphyxiated infants born at full term. ${ }^{89}$ Correlation between CK-BB activity and the neurological results of perinatal asphyxia has been reported, but the damaged survivors have been few. ${ }^{10} 11$

The aim of this follow up study was to find out if serum CK-BB activity on the first day of life is an indicator of perinatal brain damage.

\section{Patients and methods}

The infants studied were born in $1982-5$ at the Women's Hospital, and, if necessary, treated at the neonatal intensive care unit of the Children's Hospital, University of Helsinki. The study protocol was approved by the ethical committees of both hospitals. Informed consent was obtained from both parents if possible.

Three groups of infants were studied. The acute asphyxia group infants (table 1) were born after uneventful pregnancy and spontaneous onset of labour, but had severe intrapartum asphyxia, defined as an Apgar score of 6 or less at 5 minutes $(n=24)$ or an umbilical arterial $\mathrm{pH}$ of 7.05 or less $(n=7)$. Two infants died of cerebral infarction at the ages of 1 and 8 days, and one died of asphyxia and septicaemia at the age of 14 hours.

The high risk pregnancy group (table 1) included nine infants with intrauterine growth retardation (less than two standard deviations below the mean) not associated with pre-eclampsia, and 61 infants born to mothers with severe pre-eclampsia. Forty eight fetuses had abnormal heart rate patterns before birth necessitating delivery by caesarean section in 40 cases. Fifty two infants were delivered between 25 and 36 weeks' gestation, and 31 infants needed intensive care. Seven infants died; two had 
Table 1 Clinical characteristics of subjects studied

\begin{tabular}{|c|c|c|c|}
\hline & $\begin{array}{l}\text { Infants with } \\
\text { acute asphyxia } \\
(n=31)\end{array}$ & $\begin{array}{l}\text { High risk } \\
\text { pregnancy } \\
(n=70)\end{array}$ & $\begin{array}{l}\text { Very low } \\
\text { birthweight infants } \\
(n=47)\end{array}$ \\
\hline Gestational age (weeks)* & $39 \cdot 4(2 \cdot 3)$ & $34 \cdot 0(3 \cdot 5)$ & $29.0(2 \cdot 1)$ \\
\hline Birth weight $(\mathrm{g})^{*}$ & $3470(770)$ & $1830(730)$ & $1185(210)$ \\
\hline Small for gestational age & 1 & 32 & 4 \\
\hline Male:female & $13: 18$ & $39: 31$ & $23: 24$ \\
\hline Twin or triplet & 2 & 6 & 17 \\
\hline \multicolumn{4}{|l|}{ Mode of delivery: } \\
\hline Vaginal & 14 & 16 & 21 \\
\hline Caesarean section & 17 & 54 & 26 \\
\hline \multicolumn{4}{|l|}{ Umbilical arterial $\mathrm{pH}$ : } \\
\hline Median (No of patients) & $7 \cdot 06(16)$ & $7 \cdot 25(50)$ & $7 \cdot 30(4)$ \\
\hline Range & $6 \cdot 57-7 \cdot 29$ & $7 \cdot 12-7 \cdot 39$ & $7 \cdot 27-7 \cdot 33$ \\
\hline \multicolumn{4}{|l|}{ Apgar score: } \\
\hline \multirow{2}{*}{ At one minute $\begin{array}{r}0-3 \\
4-7\end{array}$} & 21 & 6 & 16 \\
\hline & 8 & 19 & 19 \\
\hline \multirow{2}{*}{ At five minutes $\begin{array}{r}0-3 \\
4-7\end{array}$} & 14 & 0 & 3 \\
\hline & 11 & 14 & 22 \\
\hline \multicolumn{4}{|l|}{ Neonatal diagnoses: } \\
\hline Respiratory distress syndrome & 1 & 14 & 27 \\
\hline \multicolumn{4}{|l|}{ Hypoxic-ischaemic encephalopathy: } \\
\hline Mild & 5 & 1 & 0 \\
\hline Moderate & 8 & 0 & 0 \\
\hline Severe & 6 & 0 & 0 \\
\hline \multicolumn{4}{|c|}{ Periventricular or intraventricular haemorrhage: } \\
\hline Grade I & 1 & 5 & 9 \\
\hline Grade II & 0 & 1 & 4 \\
\hline Grade III & 0 & 2 & 3 \\
\hline Grade IV & 0 & 2 & 3 \\
\hline Mechanical ventilation $>12$ hours & 19 & 22 & 37 \\
\hline Treatment with phenobarbitone & 13 & 10 & 20 \\
\hline Death: neonatal/later & $3 / 0$ & $6 / 1$ & $3 / 3$ \\
\hline
\end{tabular}

${ }^{*}$ Data expressed as mean (SD).

intracerebral haemorrhages and a third had infarction of the brain, but the other four infants had no signs of hypoxic-ischaemic brain damage at necropsy.

The very low birthweight group infants (less than $1500 \mathrm{~g}$, table 1) were born after the acute onset of labour, or an acute maternal complication with no previous complications of pregnancy. All received intensive care for a median of 33 days. One infant died of renal tubular necrosis and intracerebral haemorrhage and one of tension pneumothorax and ischaemic brain lesions, but in the remaining four deaths no signs of hypoxic brain damage were found at necropsy.

Within each study group infants with adverse outcomes were compared with those with normal outcome. For ethical reasons no blood samples were taken from healthy control infants.

Blood samples were obtained at the age of 6-14 hours (median sampling age 10 hours). Serum was separated and stored at $-20^{\circ} \mathrm{C}$ until analysis. Creatine kinase activity was measured using a Scandinavian standard method. ${ }^{12}$ The proportion of activity due to the BB-isoenzyme was determined by an electrophoretic method on cellulose acetate, with a sensitivity of 2 U/l (Helena CPK Electrophoresis Procedure, Super CPK Isoenzyme Kit 5449).

Umbilical arterial blood $\mathrm{pH}$ was obtained from most of the asphyxiated and high risk pregnancy cases but only from four infants in the very low birthweight group. The Apgar score was routinely assigned at the age of 1 and 5 minutes by the attending paediatrician or midwife. Brain ultrasound examination was performed with a sector scanner (ATL, 5 or $7 \mathrm{MHz}$ transducer) at least once during the first week and in preterm infants repeatedly during the first month.

Neurodevelopmental follow up was carried out by two paediatric neurologists unaware of the perinatal history. The methods have previously been reported in detail. ${ }^{1314}$ The end point for the present evaluation was an examination at $2 \cdot 2-2 \cdot 5$ years of age, which included estimation of developmental quotient by a psychologist. The quotient was derived from the Bayley mental scale of infant development or the corresponding Terman-Merrill-Hellström test of mental and motor development, ${ }^{14}$ and it was corrected for prematurity.

Based on these examinations the children were 
classified into four outcome categories: normal outcome, mild motor impairment (slight or transient abnormality in muscle tone or an abnormal pattern of motor development), cerebral palsy, ${ }^{15}$ or developmental delay (mental developmental quotient less than 100, no motor dysfunction). Because neurodevelopmental delay without motor impairment can seldom be ascribed to perinatal asphyxia, perinatal brain damage was considered to be present in infants who died with hypoxic-ischaemic lesions of the brain and in infants who had cerebral palsy or mild motor impairment.

Data analyses were performed using the BMDP statistical software (BMDP Statistical Software Inc). Natural logarithmic transformation was done for CK-BB activities to correct for skewness of the distribution. The Mann-Whitney test, analysis of variance, and $\chi^{2}$ tests were applied for comparison between the outcome categories as appropriate. Linear regression was used for analysing the associations between CK-BB activity and the measures of asphyxia, $\mathrm{pH}$, and the Apgar score, as well as developmental quotient.

\section{Results}

The outcome of the infants in the three study groups is shown in table 2. Perinatal brain damage was present in a total of 38 infants: 16 had mild motor impairment, 14 cerebral palsy, and eight died of hypoxic-ischaemic lesions in the brain.

In the acute asphyxia group, CK-BB activity did not correlate with the Apgar score or with cord $\mathrm{pH}$ in the 16 infants who had this determined. CK-BB activities were similar in all three severity grades of hypoxic-ischaemic encephalopathy ${ }^{16}$ and in those infants without it. No correlation was found between CK-BB activity and developmental quotient at 2 years. $\mathrm{CK}-\mathrm{BB}$ activities in the infants with normal outcome and those with perinatal brain damage are shown in fig 1 . The two infants with developmental delay without motor impairment (not included in the figure) had CK-BB activities below $2 \mathrm{U} / \mathrm{l}$.

In the high risk pregnancy group, $\mathrm{CK}-\mathrm{BB}$ did not correlate with the 5 minute Apgar score, cord $\mathrm{pH}$, gestational age, or the degree of intrauterine growth retardation. Because CK-BB activities were similar in infants with grades I-III of intraventricular haemorrhage and in those without, the presence of

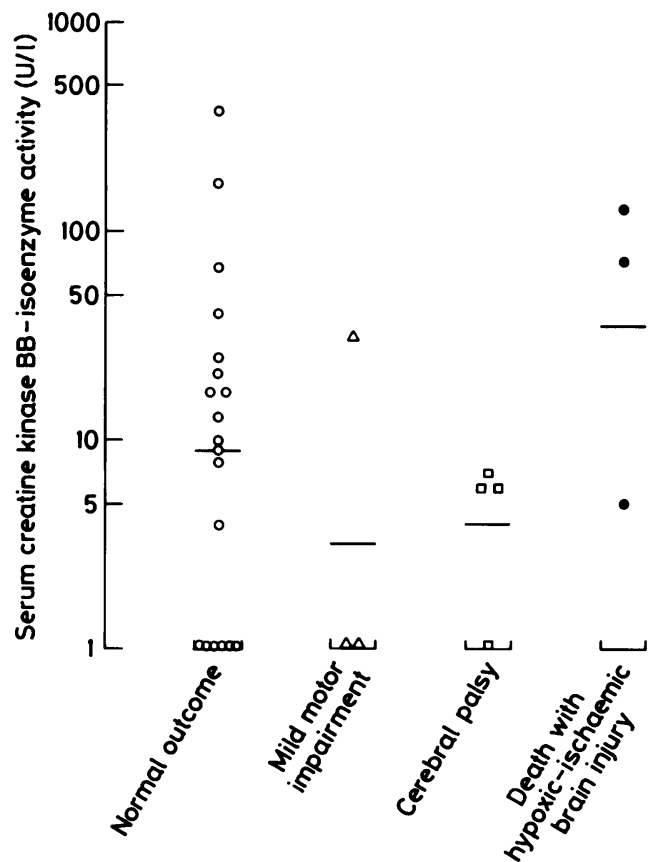

Fig 1 Serum creatine kinase BB-isoenzyme activity in infants with acute birth asphyxia in relation to outcome at 2 years. Horizontal bars indicate the geometric mean of each category.

Table 2 Outcome of study subjects: deaths and results of neurodevelopmental follow up at $2 \cdot 5$ years

\begin{tabular}{llll}
\hline & $\begin{array}{l}\text { Infants with } \\
\text { acute asphyxia }\end{array}$ & $\begin{array}{l}\text { High risk } \\
\text { pregnancy }\end{array}$ & $\begin{array}{l}\text { Very low } \\
\text { birthweight infants }\end{array}$ \\
\hline Normal outcome & 19 & 50 & 27 \\
Mild motor impairment & 3 & 7 & 6 \\
Cerebral palsy, total & 4 & 2 & 8 \\
$\quad$ Diplegia & 1 & 0 & 6 \\
$\quad$ Tetraplegia & 3 & 0 & 0 \\
$\quad$ Hemiplegia & 0 & 1 & 0 \\
$\quad$ Dystonia & 0 & 1 & 0 \\
$\quad$ mevelopmental delay without & 2 & 4 & 2 \\
Death with brain damage & 3 & 3 & 4 \\
Death without brain damage & 0 & 4 & 0 \\
\hline
\end{tabular}


haemorrhage was not a confounding factor when analysing CK-BB activity in relation to outcome. No correlation was found between CK-BB activity and developmental quotient. The infants who died with hypoxic-ischaemic brain lesions had significantly higher values (geometric mean $330 \mathrm{U} / \mathrm{l}$ ) than those with normal outcomes $(13 \mathrm{U} / \mathrm{l})$, but infants with cerebral palsy or mild motor impairment did not differ from normal infants (fig 2); neither did the infants who died without hypoxic-ischaemic brain lesions $(30 \mathrm{U} / \mathrm{l})$ or those who had developmental delay without motor impairment.

In the very low birthweight group, no correlation was found between CK-BB activity, Apgar scores, or gestational age. The enzyme activities were similar in infants with all grades of intraventricular haemorrhage and in infants without. No correlation was found between CK-BB activity and the developmental quotient. The geometric means in infants with normal outcome, mild motor impairment, and cerebral palsy were 14,29 , and $20 \mathrm{U} / \mathrm{l}$, respectively (fig 3 ). The two infants who died with brain damage had high values. The range of CK-BB activity in the four infants who died without brain injury was 7-31 U/l.

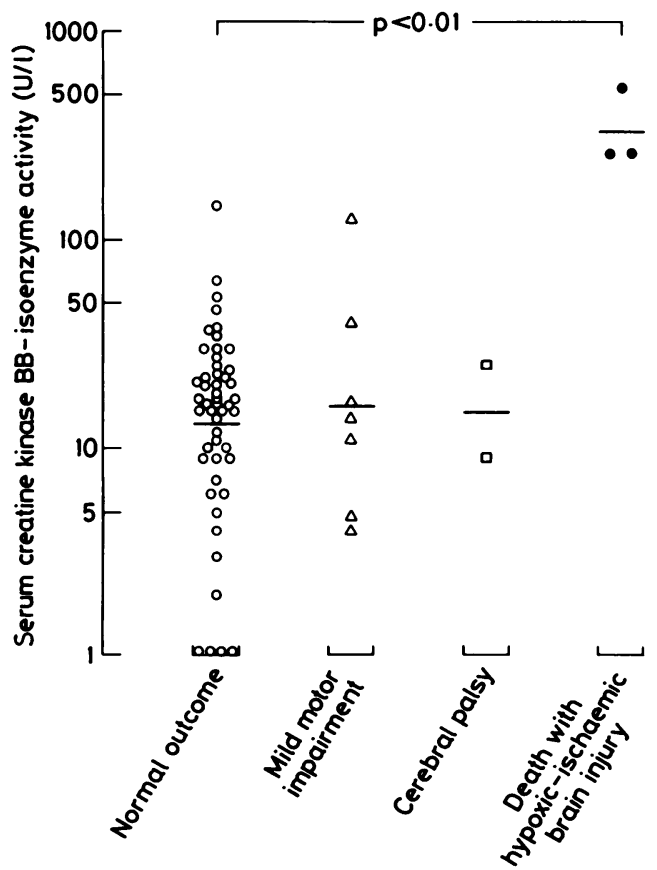

Fig 2 Serum creatine kinase BB-isoenzyme activity in infants born after high risk pregnancy in relation to outcome at 2 years.

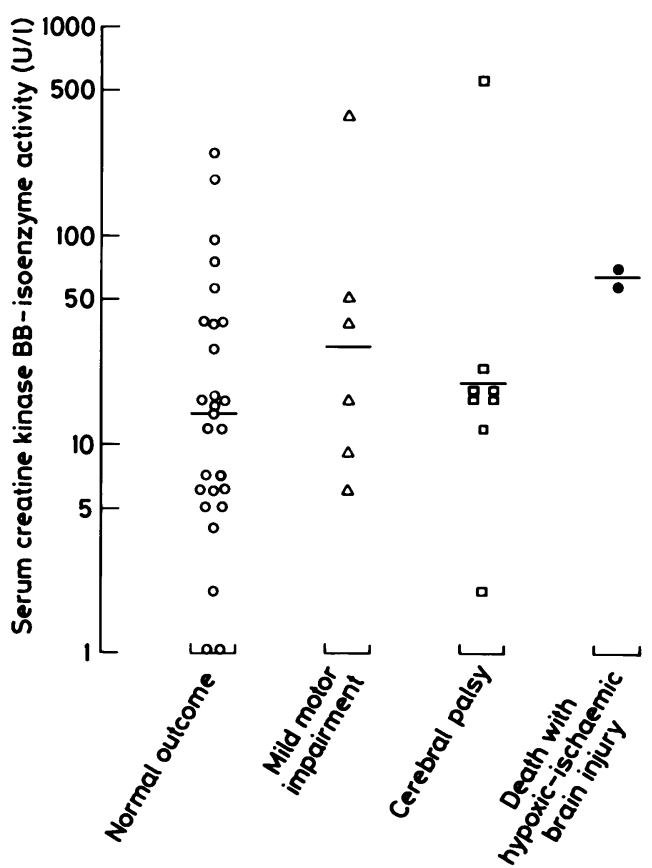

Fig 3 Serum creatine kinase BB-isoenzyme activity in very low birthweight infants in relation to outcome at 2 years.

CK-BB activities were similar in infants treated with phenobarbitone, which was given in most cases as part of a prophylactic trial, ${ }^{14}$ and in those not receiving the drug (geometric means 16 and $13 \mathrm{U} / 1$, respectively). When all three study groups were combined, infants who died with brain damage had significantly higher CK-BB activities than those with normal outcome $(12 \mathrm{U} / \mathrm{l})$, the mean difference was $82 \mathrm{U} / 1$ (95\% confidence interval 31 to $219 \mathrm{U} / \mathrm{l}$ $(p<0 \cdot 001)$. The infants with mild motor impairment or cerebral palsy (geometric mean 15 and $12 \mathrm{U} / \mathrm{l}$, respectively), however, did not differ from the normal ones.

\section{Discussion}

The method for determining CK-BB activity used in the present study has a sensitivity of $2 \mathrm{U} / \mathrm{l}$, which is sufficient for the present purpose as CK-BB activity in healthy newborn infants is higher than in adults. ${ }^{17}$ CK-BB activity in cord blood is about twice that in maternal blood, ${ }^{9}$ and increases after birth with a peak at the age of about 5-10 hours. ${ }^{1011} 17$ The mode of delivery does not affect the CK-BB activity in cord blood or later during the first day. ${ }^{17} 18$

Although the main source of serum CK-BB in 
man is the brain, this isoenzyme is found in many tissues-for example, gastrointestinal tract, kidney, lung, liver, uterus, and placenta. ${ }^{19}$ The vessel walls of both umbilical artery and vein have high CK-BB activities, even higher than placenta. ${ }^{20}$ Thus cord blood CK-BB activity may be partly derived from uterine, placental, or umbilical tissues and cannot be considered specific for the fetal brain. Increasing activity in blood after birth, however, must be released from tissues in the newborn infant, and probably mainly the brain. This is suggested by the finding that infants with necrotising enterocolitis, or lung or kidney disease, do not have higher activities than control infants, whereas infants with severe asphyxia and neurological damage do. ${ }^{9}$ In the present study the age at blood sampling (10 hours on average) was chosen on the basis of previous studies ${ }^{10}{ }^{17}$ close to the supposed peak activity.

In newborn infants who died of severe brain damage, serum CK-BB on day 1-4 was significantly increased. ${ }^{8} \mathrm{By}$ repeated serum $\mathrm{CK}-\mathrm{BB}$ measurements, the outcome at a mean age of 7 months was predictable in $77 \%$ of 22 severely asphyxiated term infants. ${ }^{10}$ In another study of 33 asphyxiated infants born at full term, adverse outcome could be predicted by CK-BB activity at the age of 4 hours. ${ }^{11}$ Adverse outcome in both these studies, however, was usually death, as only three in the first and four in the second study survived with neurological abnormalities.

In the present study, severe brain damage leading to death in the neonatal period was associated with high CK-BB activities, especially after high risk pregnancy. Cerebral palsy or mild motor impairment, however, could not be predicted.

Brain injury in the young infant is not necessarily associated with the process of birth. Although most infants in the high risk pregnancy group had intrapartum asphyxia, the insult might have occurred earlier. In the other two groups damage during labour or at birth seems probable.

In cases with fatal intracerebral haemorrhage, CK-BB activity was high, whereas infants with grades I-III intraventricular haemorrhage had activities similar to those without bleeding. Significantly higher CK-BB activities on the first day have previously been found in infants with haemorrhage, ${ }^{7}$ but the extent of the bleeding was more severe than in the present study.

It is likely that the release of CK-BB from damaged neurones and through the blood brain barrier is dependent on the severity of the insult. Enzyme activities in the cerebrospinal fluid of newborn infants could be a better predictor of brain damage than those in serum, as is the case in adults. ${ }^{7}$ The aim of this study, however, was to look for a simple serum assay with the potential for screening infants at risk for brain damage, for which purpose a lumbar puncture would not be suitable. Unfortunately, serum CK-BB activity does not seem to be accurate enough.

In conclusion, a single measurement of $\mathrm{CK}-\mathrm{BB}$ activity on the first day of life cannot be used as a prognostic indicator of long term neurological outcome, but high activities in critically ill newborn infants indicate a risk of neonatal death.

This study was supported by grants from the Foundation for Paediatric Research, the Sigrid Juselius Foundation, the Signe and Ane Gyllenberg Foundation, and Finska Läkaresällskapet. I thank Peter Elg for help with CK-BB determinations.

\section{References}

1 Hagberg B, Hagberg G, Olow I. The changing panorama of cerebral palsy in Sweden. IV. Epidemiological trends 1959-78. Acta Paediatr Scand 1984;73:433-40.

2 Powell TG, Pharoah PO, Cooke RI. Survival and morbidity in a geographically defined population of low birthweight infants. Lancet 1986; :539-43.

${ }^{3}$ Nelson KB, Ellenberg JH. Apgar scores as predictors of chronic neurologic disability. Pediatrics 1981;68:36-44.

${ }^{4}$ Ruth VJ, Raivio KO. Perinatal brain damage: predictive value of metabolic acidosis and Apgar score. Br Med J 1988;297:24-7.

5 Kaste M, Somer H, Konttinen A. Brain-typical creatine kinase isoenzyme. Arch Neurol 1977;34:142-4.

6 Hans P, Born JD, Chapelle J-P, Milbouw G. Creatine kinase isoenzymes in severe head injury. $J$ Neurosurg 1983;58:689-92.

7 Shields WD, Feldman RC. Serum CK-BB isoenzyme in preterm infants with periventricular hemorrhage. J Pediatr 1982;100: 464-8.

${ }^{8}$ Becker M, Menzel K. Brain-typical creatine kinase in the serum of newborn infants with perinatal brain damage. Acta Paediatr Scand 1978;67:177-80.

${ }^{9}$ Cuestas RA. Creatine kinase isoenzymes in high-risk infants. Pediatr Res 1980;14:935-8.

10 Walsh P, Jedeikin R, Ellis G, Primhak R, Makela SK. Assessment of neurologic outcome in asphyxiated term infants by use of serial CK-BB isoenzyme measurement. $J$ Pediatr 1982;101:988-92.

"Fernandez F, Verdu A, Quero J, Perez-Higueras A. Serum CPK-BB isoenzyme in the assessment of brain damage in asphyctic term infants. Acta Paediatr Scand 1987;76:914-8.

${ }^{12}$ Hörder M, Magid E, Pitkänen E, et al. Recommended method for the determination of creatine kinase in blood modified by the inclusion of EDTA. Scand J Clin Lab Invest 1979;39:1-5.

13 Ruth V, Autti-Rämö I, Granström M-L, Korkman M, Raivio KO. Prediction of perinatal brain damage by cord plasma vasopressin, erythropoietin, and hypoxanthine. J Pediatr 1988; 113:885-5.

14 Ruth V, Virkola K, Paetau R, Raivio KO. Early high-dose phenobarbital treatment for prevention of hypoxic-ischemic brain damage in very low birth weight infants. $J$ Pediatr 1988;112:81-6.

15 Hagberg B, Hagberg G, Olow I. The changing panorama of cerebral palsy in Sweden 1954-1970. II. Analysis of the various syndromes. Acta Paediatr Scand 1975;64:193-200.

16 Fenichel GM. Hypoxic-ischemic encephalopathy in the newborn. Arch Neurol 1983;40:261-6.

17 Jedeikin R, Makela S, Shennan AT, Rowe RD, Ellis G. Creatine kinase isoenzymes in serum from cord blood and the 


\section{Ruth}

blood of healthy full-term infants during the first three postnatal days. Clin Chem 1982;28:317-22.

${ }^{18}$ Ezitis J, Finnström O, Hedman G, Rabow L. CKBB-enzyme activity in serum in neonates born after vaginal delivery and cesarean section. Neuropediatrics 1987;18:146-8.

${ }^{19}$ Neumeier D. Tissue specific and subcellular distribution of creatine kinase isoenzymes. In: Lang $\mathrm{H}$, ed. Creatine kinase isoenzymes. Pathophysiology and clinical application. Berlin: Springer Verlag, 1981: 85-115.
${ }^{20}$ Kumpel B, Wood SM, Anthony PP, Brimblecombe FS. Umbilical cord serum creatine kinase $\mathrm{BB}$ in the diagnosis of brain damage in the newborn: problems in interpretation Areil $D$ is Child 1983;58:382-3.

Correspondence and requests for reprints to Dr V Ruth, Children's Hospital, Stenbäckinkatu 11, 00290 Helsinki, Finland.

Accepted 12 October 1988 